\title{
ANTAGONISM WITHIN POPULATIONS OF MICRO-ORGANISMS FROM NORMAL HUMAN SKIN
}

\author{
Patricia Wright and C. S. Terry \\ Postgraduate School of Studies in Pharmacy, University of Bradford, Bradford, West \\ Yorkshire BD7 IDP
}

\begin{abstract}
SUMmaRY. The skin flora of 20 normal subjects was sampled from $7-\mathrm{cm}^{2}$ sites on the volar forearm, forehead and ball of the foot. Interactions between all aerobic and anaerobic strains isolated from the same site were examined by a deferred-antagonism technique. Seventeen subjects possessed inhibitory strains on at least one skin site. Of the Micrococcaceae tested, $20.6 \%$ were inhibitory. Of the aerobic diphtheroids, more strains were sensitive $(19.2 \%)$ than inhibitory $(5 \cdot 1 \%)$. Inhibitory Micrococcaceae and aerobic diphtheroids revealed intergeneric and intrageneric inhibition. Antagonistic propionibacteria were found $(7 \cdot 4 \%)$ but no sensitive strains. Several Micrococcaceae were specifically antagonistic towards only one strain isolated from the same skin site; no sensitive strains from other skin sites or other subjects were found. Quantitative sampling showed that only $17.5 \%$ of the inhibitory strains clearly dominated their skin sites numerically.
\end{abstract}

\section{INTRODUCTION}

The role of "antibiotic"-producing strains of bacteria in the microbial ecology of the skin is controversial and has been well reviewed by Woodroffe and Shaw (1974) and by Noble and Pitcher (1978). The interactions of skin Micrococcaceae, in particular, are extensively documented in these reviews.

Hsu and Wiseman (1967) found that $6 \%$ of the coagulase-positive and coagulase-negative staphylococci they studied produced antibiotics, but Pillsbury and Rebell (1952) found no evidence of inhibition by 100 strains of skin Micrococcaceae or by 10 strains of skin diphtheroids. Selwyn and Ellis (1972) reported that $20 \%$ of normal persons carried antibiotic-producing bacteria on their skin and Selwyn (1975) found antibiotic-producing bacteria on the healthy intact skin of about $23 \%$ of subjects, the active strains predominating in $38 \%$ of these; $19 \%$ of dermatological patients carried inhibitory strains, which constituted the predominant flora in $78.4 \%$ of these subjects. Selwyn (1975) concluded that carriage of an inhibitory strain confers an advantage on diseased skin but not on healthy skin. Noble and Willie (1980) were, however, unable to confirm these results and observed that 
carriage of inhibitory strains did not protect against colonisation by Staphylococcus aureus. They recognised that only $10 \%$ of patients carry inhibitory strains.

Holland, Cunliffe and Eady (1979) discerned no difference between the prevalence of inhibitory strains on normal skin and skin bearing acne lesions, and they established that inhibitory strains of Propionibacterium acnes outnumbered inhibitory Micrococcaceae by four to one on the face and the back.

Antagonism by aerobic coryneforms isolated from the skin has not been studied in detail, although Somerville (1972) observed bacteriocine production by these organisms and Noble, Willie and Admawi (1979) reported production of a peptide antibiotic with a molecular weight of approximately 1200 by some skin coryneforms.

The main discrepancies in these surveys may have arisen from differences in technique. Thus, the methods of demonstrating antagonism varied from simultaneous antagonism (Selwyn and Ellis, 1972) to deferred antagonism (Holland et al., 1979). For indicator organisms, Pillsbury and Rebell (1952) used strains not originating from the skin. Hsu and Wiseman (1967) used only one indicator strain to test over 1400 Micrococcaceae in initial screening, while Pryjma et al. (1971a) used two indicator strains, one staphylococcus and one diphtheroid, as did Selwyn and Ellis (1972). Holland et al. (1979) used 12 strains of $S$. epidermidis biotype 1 , and 20 strains of $P$. acnes as indicators. Other factors of importance may be the diffusibility of the inhibitor, the dilution of the indicator strains, the choice of culture medium, the age of cultures and the time and temperature of incubation.

The purpose of the present study was to clarify potential inhibition in vivo by examination of inhibition patterns between all bacterial strains isolated from the same skin site on the same subject.

\section{MATERIALS AND METHODS}

Materials. Tryptone Soya Agar (TSA), Reinforced Clostridial Agar (RCA), Malt Extract Agar (MEA), Brain Heart Infusion Agar (BHIA) and yeast extract were from Oxoid Limited, Wade Road, Basingstoke, Hampshire RG24 0PW. Triton X-100 (Octylphenoxypolyethoxyethanol) and Tween 80 (polyoxyethylene sorbitan mono-oleate) were from the Sigma London Chemical Company Limited, Fancy Road, Poole, Dorset BH17.

Subjects. Twenty healthy subjects, 13 male and seven female, were chosen from amongst members of the University of Bradford. Their ages ranged from 22 to 53 years.

Sampling sites were the volar surface of the forearm ("non-special" skin), the forehead (sebaceous area with high populations of propionibacteria) and the ball of the foot (cornified area with many sweat ducts).

Isolation and identification of strains. The skin flora was sampled by the cup-scrub technique of Williamson and Kligman (1965). The sampling area of $7 \mathrm{~cm}^{2}$ was delineated with a sterile Perspex cylinder and two one-minute scrubs were done with sterile $0.1 \%(w / v)$ Triton X-100 in $0.075 \mathrm{M}$ phosphate buffer. The samples were pooled and two tenfold dilutions were made in sterile $0.05 \%$ Triton $X-100$ in $0.0375 \mathrm{~m}$ phosphate buffer. From the original sample and from the two dilutions, $0 \cdot 1 \mathrm{ml}$ was plated out on TSA and TSA containing $0.5 \%(\mathrm{v} / \mathrm{v})$ Tween 80 for aerobes, RCA for anaerobes and MEA containing $0.005 \%(\mathrm{w} / \mathrm{v})$ chloramphenicol for dermatophytes. Aerobic plates were incubated at $37^{\circ} \mathrm{C}$ for $48 \mathrm{~h}$ and anaerobic plates for 5 days in 
a Baird and Tatlock anaerobic jar with Oxoid Gas-Kits. Plates for dermatophytes, stored at $25^{\circ} \mathrm{C}$, were examined at intervals for up to 14 days. Colony types were counted on the most suitable plates and counts $/ \mathrm{cm}^{2}$ of the sampled area were calculated. Representative colonies were transferred to slopes and plated out to check for purity. Facultative anaerobes on RCA plates were detected by aerobic subculture.

Gram-positive, catalase-positive cocci were classified according to Baird-Parker (1974). Aerobic, gram-positive, catalase-positive diphtheroids were morphologically variable and were classified according to Evans (1968). Anaerobic gram-positive diphtheroids were designated as propionibacteria although different colonial types isolated from the same skin site were noted. Isolates that did not belong to the above categories were classified according to Cowan (1974). The only dermatophyte isolated was stained with lactophenol cotton blue and checked microscopically.

Strains were identified after testing for inhibition because preliminary experiments had shown that the inhibitory ability of some strains was unstable.

Designation of strains. Subjects were numbered 1 to 20 and skin sites were designated $\mathrm{A}=$ volar forearm, $\mathrm{B}=$ forehead, $\mathrm{C}=$ ball of foot. Micrococcaceae were coded according to Baird-Parker (1974) as follows: $\mathrm{SA}=S$. aureus; SE 1 to $4=S$. epidermidis and biotype; SS 1 to $4=S$. saprophyticus and biotype; $M=$ Micrococcus. Aerobic diphtheroids were coded Diphth. A to G (Evans, 1968). Hence 1A SE 1 was a strain of $S$. epidermidis biotype 1 isolated from the forearm of subject 1 .

Demonstration of antagonism. All strains isolated from a single site on one subject constituted a "test group"; hence there were 60 groups. Each strain within each group was tested for inhibitor production against all other strains in the test group and for sensitivity to inhibitors produced by all other strains.

The method and medium used to demonstrate antagonism reproducibly were selected after preliminary experiments with skin strains and known inhibitory strains and a deferredantagonism technique was chosen. Overnight broth cultures of aerobic organisms within a test group were stab-inoculated with a multipoint device into TSA containing $0.5 \%(\mathrm{w} / \mathrm{v})$ yeast

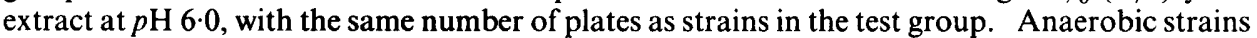
were stab-inoculated in BHIA at $p \mathrm{H} 6.0$. Plates were incubated at $37^{\circ} \mathrm{C}$, the aerobic ones for $36-48 \mathrm{~h}$ and the anaerobic ones for 4 days. Growth around the stabs was removed by scraping and the plates were exposed to chloroform according to the method of Bauernfeind and Burrows (1978). The plates were seeded by flooding with 1 in 50 dilutions of overnight broth cultures of each strain in the test group and then incubated at $37^{\circ} \mathrm{C}$, overnight for aerobic indicator strains and 4 days for anaerobic indicator strains. Inhibition zones were recorded.

Because Fedotova (1967, cited by Ivanov, 1970) had stated that about $70 \%$ of bacteriocines produced by skin staphylococci were sensitive to chloroform, comparative tests were made between the bactericidal action of ultraviolet (UV) light and chloroform. In the UV experiments plates were exposed in a Hanovia Bactericidal Unit $(\lambda=2537 \AA$; Hanovia Lamps, Slough, Berks) for $20 \mathrm{~min}$ and seeded as above. No difference between the methods was found, except that one staphylococcus showed an inhibition zone on the UV-irradiated plate but not on the chloroform-treated plate.

Bacterial counts were done on original skin washings to determine whether inhibitor production was a property of "dominant" strains. "Dominance" is difficult to define because Leyden et al. (1975) have shown that on the face P. acnes may outnumber Micrococcaceae by ten to one and, moreover, counts may be affected by dilution (Evans et al., 1950). These factors were taken into account when assessments were made.

\section{RESULTS}

Of the 20 subjects, three showed no inhibition in all test groups, seven displayed inhibition in one group, eight in two groups and two showed inhibition in all three test groups. Nine subjects had inhibitory strains on the forearm, seven on the forehead and 13 on the ball of the foot. Ten test groups 
yielded more than one inhibitory strain and 12 test groups possessed more than one sensitive strain (table I).

Forty of the 295 strains $(13.6 \%)$ produced inhibitors against strains in the same test group (table II), and 47 of the 295 strains $(15.9 \%)$ were sensitive to inhibitors produced by strains in the same test group.

Table III shows that the highest incidence of inhibition was found between the Micrococcaceae. There were more sensitive aerobic diphtheroids than inhibitory strains. Inhibitory Micrococcaceae and aerobic diphtheroids showed intergeneric and intrageneric inhibition. Four inhibitory propionibacteria were found; all were active against Micrococcaceae but not against aerobic diphtheroids. Sensitive propionibacteria were not discovered.

TABLE I

Inhibition patterns between strains'of bacteria isolated from the same skin site of the same subject

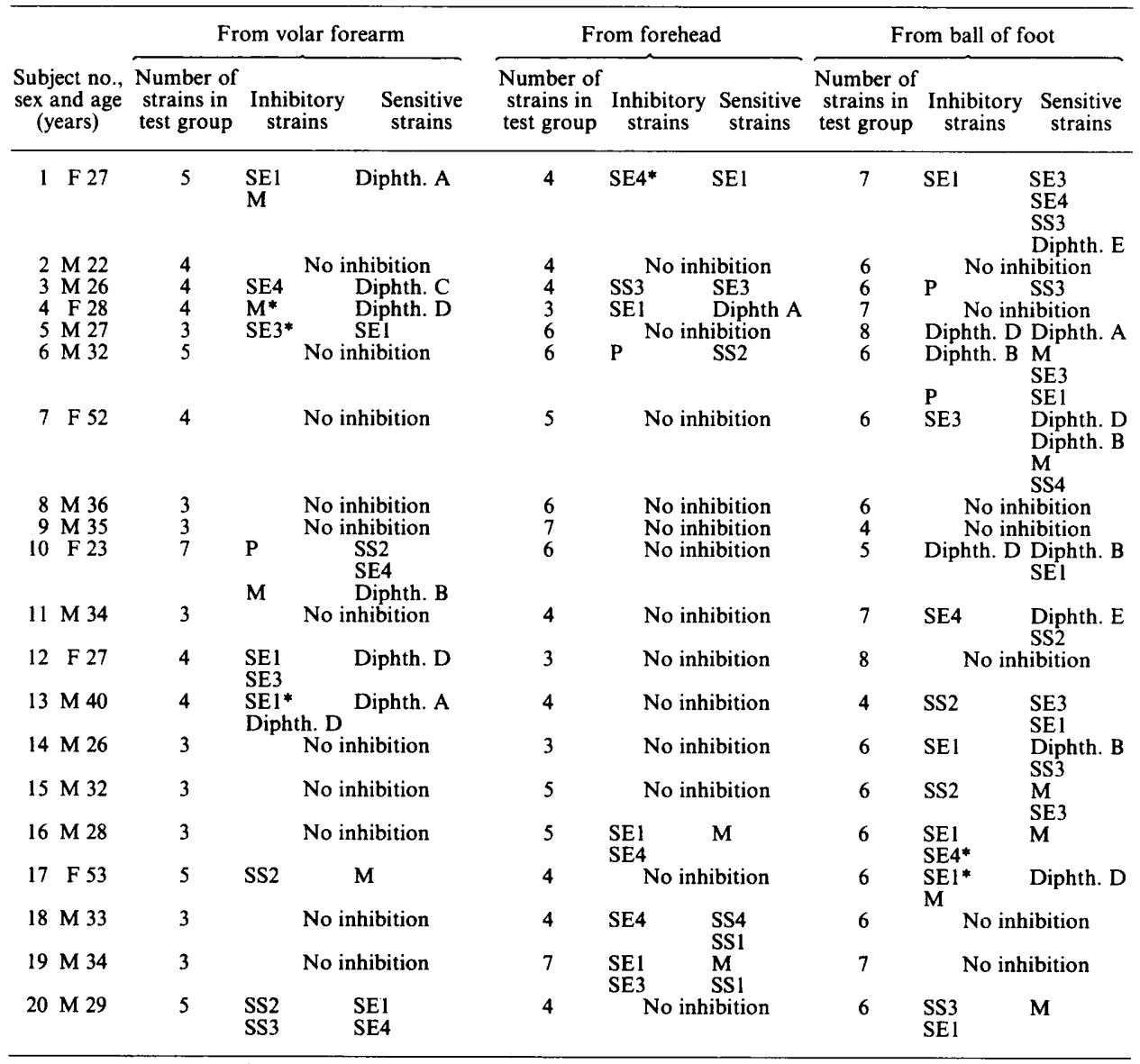

SE1 to $4=S$. epidermidis and biotype; SS1 to $4=S$. saprophyticus and biotype; $M=$ genus Micrococcus (Baird-Parker, 1974); Diphth. A to $G=$ aerobic diphtheroids (Evans, 1968); $P=$ genus Propionibacterium.

* Micrococcaceae with very limited inhibitory activity, i.e., not active against strains isolated from other skin sites or other subjects. 
TABLE II

Inhibitory and sensitive strains isolated from the healthy skin of 20 subjects

\begin{tabular}{|c|c|c|c|c|c|c|c|c|}
\hline \multirow{3}{*}{$\begin{array}{l}\text { Classification } \\
\text { of strains }\end{array}$} & \multicolumn{8}{|c|}{ Number of inhibitory or sensitive strains/number isolated (and percentage) from } \\
\hline & \multicolumn{2}{|c|}{ volar forearm } & \multicolumn{2}{|c|}{ forehead } & \multicolumn{2}{|c|}{ ball of foot } & \multicolumn{2}{|c|}{ all sites } \\
\hline & I & $\mathrm{S}$ & I & $\mathrm{S}$ & I & $\mathrm{S}$ & I & $\mathbf{S}$ \\
\hline Micrococcaceae & $\begin{array}{l}12 / 41 \\
(29 \cdot 3)\end{array}$ & $\begin{array}{r}6 / 41 \\
(14 \cdot 6)\end{array}$ & $\begin{array}{r}8 / 52 \\
(15 \cdot 4)\end{array}$ & $\begin{array}{r}8 / 52 \\
(15 \cdot 4)\end{array}$ & $\begin{array}{l}12 / 62 \\
(19 \cdot 4)\end{array}$ & $\begin{array}{c}18 / 62 \\
(29 \cdot 0)\end{array}$ & $\begin{array}{l}32 / 155 \\
(20 \cdot 6)\end{array}$ & $\begin{array}{l}32 / 155 \\
(20 \cdot 6)\end{array}$ \\
\hline Aerobic diphtheroids & $\begin{array}{l}1 / 20 \\
(5 \cdot 0)\end{array}$ & $\begin{array}{r}6 / 20 \\
(30 \cdot 0)\end{array}$ & $0 / 19$ & $\begin{array}{l}1 / 19 \\
(5 \cdot 3)\end{array}$ & $\begin{array}{l}3 / 39 \\
(7 \cdot 7)\end{array}$ & $\begin{array}{r}8 / 39 \\
(20.5)\end{array}$ & $\begin{array}{l}4 / 78 \\
(5 \cdot 1)\end{array}$ & $\begin{array}{l}15 / 78 \\
(19 \cdot 2)\end{array}$ \\
\hline Propionibacteria & $\begin{array}{l}1 / 15 \\
(6.7)\end{array}$ & $0 / 15$ & $\begin{array}{l}1 / 20 \\
(5 \cdot 0)\end{array}$ & $0 / 20$ & $\begin{array}{r}2 / 19 \\
(10 \cdot 5)\end{array}$ & $0 / 19$ & $\begin{array}{l}4 / 54 \\
(7 \cdot 4)\end{array}$ & $0 / 54$ \\
\hline Others & $0 / 2$ & $0 / 2$ & $0 / 3$ & $0 / 3$ & $0 / 3$ & $0 / 3$ & $0 / 8$ & $0 / 8$ \\
\hline All strains & $\begin{array}{l}14 / 78 \\
(17.9)\end{array}$ & $\begin{array}{l}12 / 78 \\
(15 \cdot 4)\end{array}$ & $\begin{array}{l}9 / 94 \\
(9 \cdot 6)\end{array}$ & $\begin{array}{l}9 / 94 \\
(9 \cdot 6)\end{array}$ & $\begin{array}{l}17 / 123 \\
(13.8)\end{array}$ & $\begin{array}{l}26 / 123 \\
(21 \cdot 1)\end{array}$ & $\begin{array}{l}40 / 295 \\
(13 \cdot 6)\end{array}$ & $\begin{array}{l}47 / 295 \\
(15.9)\end{array}$ \\
\hline
\end{tabular}

$\mathrm{I}=$ inhibitory; $\mathrm{S}=$ sensitive.

TABLE III

Intergeneric and intrageneric inhibition between bacterial strains isolated from the same skin site

\begin{tabular}{l|cccc}
\hline \multirow{2}{*}{$\begin{array}{c}\text { Inhibitory } \\
\text { strains }\end{array}$} & \multicolumn{4}{|c}{ Number of sensitive strains in indicated group } \\
\cline { 2 - 5 } & Micrococcaceae & Aerobic diphtheroids & Propionibacteria & Others \\
\hline Micrococcaceae & 31 & 16 & 0 & 0 \\
Aerobic diphtheroids & 3 & 3 & 0 & 0 \\
Propionibacteria & 5 & 0 & NT & 0 \\
Others & 0 & 0 & 0 & NT \\
\hline
\end{tabular}

NT $=$ not tested.

Because very few test groups contained more than one strain of Propionibacterium intrageneric inhibition of this group was not studied.

One dermatophyte, three strains of Peptococcus, two streptococci and two gram-negative rods (not fully identified) were isolated from the test subjects. None of these showed any inhibition of strains from the same site and six were isolated from sites where inhibition was not demonstrable by any of the strains in the test group.

The total number of inhibitory strains in all test groups was 40 and of these only seven strains $(17.5 \%)$ showed clear numerical dominance at all dilutions on the skin-sampling plates.

\section{Discussion}

Pryjma, Heczko and Bobr (1971b) observed that in the nasal vestibule sensitive diphtheroid strains co-existed only sporadically with staphylococci possessing antagonistic properties. In the present survey the many strains 
isolated from the skin and capable of inhibiting other strains from the same site is surprising. The results show that inhibitory strains do not necessarily dominate healthy skin numerically but that they may control the population densities of sensitive resident organisms. Milyani and Selwyn (1978) showed that the inhibitory effect of their $\mathrm{S}^{+}{ }^{+}$strain was more pronounced on solid than in liquid media and that this can be attributed to dilution of the antibiotic in the latter. However, the inhibition of a less sensitive strain of $S$. aureus on solid media depended on the absolute and relative size of the $\mathrm{S}^{+}$inoculum; if this was too low, the S. aureus grew normally. Milyani and Selwyn (1978) stated that the physical distribution of the antibiotic-producing strain was very important and that antibiotic production would be insufficient to suppress the growth of sensitive strains if the producer strain was too widely dispersed. In a recent study with the scanning electron microscope, Malcolm and Hughes (1980) showed bacteria widely scattered in small colonies on the skin surface, a spatial relationship that may affect antibiotic sensitivity on the skin. Also, there are usually more than two strains present on a skin site and an inhibitor may be neutralised by enzymes produced by a third strain to give a stable population. Another possibility is that strains sensitive to the inhibitor on artificial media may be protected against it on the skin. Rogers (1974) demonstrated that a sucrose-supplemented medium promoted the formation of a polysaccharide layer that protected normally sensitive streptococci against a bacteriocine of Streptococcus mutans. In the present survey, spontaneous and irreversible loss of sensitivity was noted for six strains.

Selwyn (1975) discussed the role of inhibitory strains on the skin and concluded that on healthy skin the bacterial population multiplies slowly in generally dry conditions. In topical disease, however, the bacterial populations usually increase and the elevated moisture content provides more favourable conditions for diffusion of "antibiotics" and, therefore, confers an advantage on the producer strain. Staphylococcus aureus strain 502A has been used to prevent colonisation by other more virulent staphylococci, although Anthony and Wannamaker (1967) were unable to show antibiotic production by this strain. Selwyn, Marsh and Sethna (1976) demonstrated more pronounced antagonism by their $\mathrm{S}^{+}$strain in vivo than in vitro and suggested that it would be more suitable than $S$. aureus strain $502 \mathrm{~A}$ for prophylactic use on human skin. However, the importance of inhibitory strains in the skin micro-environment cannot be truly assessed until conditions in which organisms grow on the skin can be more accurately reproduced in vitro. Murphy (1975) developed a synthetic sweat solution to simulate skin conditions and Ryall, Holt and Noble (1980) used a medium containing skin keratin as the major nutrient to study antibiotic production by dermatophytes.

In the present study most strains subcultured on artificial media showed unstable inhibitor production. Six months after isolation, only six strains from subjects 1 to 10 still produced inhibitors. Similar instability has been reported by Taylor and Mayr-Harting (1970), Lachowicz and Sienienska (1976) and Holland et al. (1979).

Possible causes of inhibition between the skin bacteria are phage, 
antibiotics, bacteriocines, bacteriolytic enzymes, toxic metabolites and depletion of essential nutrients. All inhibitory strains were tested for phage by transferring a section of the inhibition zone to a sterile plate which was then overlaid with sloppy agar seeded with the sensitive strain and incubated overnight at $37^{\circ} \mathrm{C}$. Plaques formed in only two tests and these strains were not included as inhibitors in the results; strains showing auto-inhibition were also excluded.

The inhibitory patterns between strains were found to be quite different from those reported by Holland et al. (1979). They found that inhibitory $P$. acnes outnumbered inhibitory Micrococcaceae by four to one. In the present survey only four of 55 propionibacteria inhibited other strains isolated from the same skin site. On the other hand, inhibitory Micrococcaceae were found in 24 of the 60 test groups and represented $20.6 \%$ of the Micrococcaceae tested. However, Holland et al. (1979) concentrated on strains of $P$. acnes and $S$. epidermidis biotype 1 because of their interest in acne, whereas we examined total skin flora. Another important difference was our use of strains isolated from the same skin site as indicators of inhibitor production. In this way, several Micrococcaceae with very narrow inhibition spectra were isolated (table I); they were active only against one strain from the same skin site and yet the unusually sensitive strain obviously survived at that site. These strains were not inhibitory when tested against strains gathered from other skin sites or when tested against standard strains obtained from the National Collection of Type Cultures. This suggests that strains with narrow spectra of inhibitory activity are locally important in determining the skin flora; they can be easily overlooked in surveys with standard indicator strains.

Only four of the 92 aerobic diphtheroids tested were antagonistic and three of these strains were isolated from the foot. Leyden and Kligman (1979) reported overgrowth of large-colony diphtheroids in interdigital athlete's foot with severe maceration. It is possible that inhibitors provide these organisms with an advantage in hydrated conditions where inhibitors can diffuse freely.

The financial support of the Science Research Council is gratefully acknowledged.

\section{REFERENCES}

ANTHONY, B. F. AND WANNAMAKeR, L. W. 1967. Bacterial interference in experimental burns. J. exp. Med., 125, 319.

BaIRD-PARKER, A. C. 1974 . The basis for the present classification of staphylococci and micrococci. Ann. N.Y. Acad. Sci., 236, 7.

Bauernfeind, A. AND Burrows, J. R. 1978. Suggested procedure allowing the use of plastic petri dishes in bacteriocin typing. Appl. environ. Microbiol., 35, 970.

CowAN, S. T. 1974. Cowan and Steel's Manual for the identification of medical bacteria, 2nd ed., Cambridge University Press, Cambridge.

Evans, C. A., Smith, W. M., Johnston, E. A. And Giblett, E. R. 1950. Bacterial flora of the normal human skin. J. invest. Derm. 15, 305.

Evans, N. M. 1968. The classification of aerobic diphtheroids from human skin. Br.J. Derm., 80, 81 .

Holland, K. T., Cunliffe, W. J. And Eady, E. A. 1979. Intergeneric and intrageneric inhibition between strains of Propionibacterium acnes and Micrococcaceae, particularly 
Staphylococcus epidermidis, isolated from normal skin and acne lesions. J. med. Microbiol., 12, 71.

Hsu, C. Y. AND Wiseman, G. M. 1967. Antibacterial substances from staphylococci. Can. J. Microbiol., 13, 947.

IVANOV, N. A. 1970. Staphyloccocins: their properties, classification and use for typing of staphylococci. Bull. exp. Biol. Med., 69, 559.

Lachowicz, T. AND SiEnIENSKa, B. 1976. Production of staphylococcins in solid and fluid media by different strains of staphylococci and their selection. In Staphylococci and staphylococcal diseases. Proceedings of III international symposium on staphylococci and staphylococcal infections, edited by J. Jeljaszewicz, Fischer Verlag, Stuttgart, p. 593.

LEYDEN, J. J. AND KLIGMAN, A. M. 1978. Interdigital athlete's foot. Interaction of dermatophytes and resident bacteria. Archs Derm., 114, 1466.

Leyden, J. J., McGinley, K. J., Mills, O. H. And Kligman, A. M. 1975. Age-related changes in the resident bacterial flora of the human face. J. invest. Derm., 65, 379.

Malcolm, S. A. AND Hughes, T. C. 1980 . The demonstration of bacteria on and within the stratum cornum using scanning electron microscopy. Br. J. Derm., 102, 267.

Milyani, R. M. ANd Selwyn, S. 1978. Quantitative studies on competitive activities of skin bacteria growing on solid media. J. med. Microbiol., 11, 379.

MURPHY, C. T. 1975. Nutrient materials and the growth of bacteria on human skin. Trans. St John's Hosp. Derm. Soc., Lond., 61, 51.

Noble, W. C. AND PITCHER, D. G. 1978. Microbial ecology of the human skin. In Advances in microbial ecology, vol. 2, edited by M. Alexander, Plenum Press, New York, p. 245.

Noble, W. C., Willie, J. A. ANd AdmaWI, A. M. 1979. Antibiosis amongst skin microorganisms. Br. J. Derm., $101,104$.

Noble, W. C. AND WiLlie, J. A. 1980. Carriage of inhibitor-producing organisms on human skin. J. med. Microbiol., 13, 329.

Pillsbury, D. M. AND Rebell, G. 1952. The bacterial flora of the skin. Factors influencing the growth of resident and transient organisms. J. invest. Derm., 18, 173.

Pryjma, J., Bobr, J., HeczKo, P. B., KaSProwicz, A. AND KraWieC, H. 1971a. Studies on the carrier state of Staphylococcus aureus. I. Antagonistic properties of the bacterial flora of the nasal vestibule. Epidem. Rev., 25, 190.

Pryjma, J., HeczKo, P. B. AND Bobr, J. 1971b. Studies on the carrier state of Staphylococcus aureus. II. Ecologic balance of Staphylococcus aureus and diphtheroids of the nasal vestibule. Epidem. Rev., 25, 197.

ROGERS, A. H. 1974. Bacteriocin production and susceptibility among strains of Streptococcus mutans grown in the presence of sucrose. Antimicrob. Agents Chemother., 6, 547.

Ryall, C., Holt, G. AND NoBle, W. C. 1980. Production of a penicillin-like antibiotic by Trichophyton mentagrophytes on an agar based medium containing skin keratin as the major nutrient. J. appl. Bact., 48, 359.

SelwyN, S. 1975. Natural antibiosis among skin bacteria as a primary defence against infection. Br. J. Derm., 93, 487.

SelwyN, S. AND Ellis, H. 1972. Skin bacteria and skin disinfection reconsidered. Br. med. J., $1,136$.

Selwyn, S., Marsh, P. D. and Sethna, T. N. 1976. In vitro and in vivo studies on antibiotics from skin Micrococcaceae. In Chemotherapy, edited by J. D. Williams and A. M. Geddes, Plenum Press, London, Vol. 5, p. 391.

Somer ville, D. A. 1972. The microbiology of the cutaneous diphtheroids. Br.J. Derm. 86, 16.

TAYLOR, R. AND MAYR-HARTING, A. 1970. A new staphylococcal plasmid? J. gen. Microbiol., 61, proceedings, vi.

Williamson, P. AND KLIGMan, M. 1965. A new method for the quantitative investigation of cutaneous bacteria. J. invest. Derm., 45, 498.

Woodroffe, R. C. S. AND ShAw, D. A. 1974. Natural control and ecology of microbial populations on skin and hair. In The normal microbial flora of man, edited by F. A. Skinner and J. G. Carr, Academic Press, London, p. 13. 